\section{B A Institute of \\ YK Business Administration \\ 六下 \\ Karachi \\ Leadership and Ideas for Tomorrow}

Business Review

Volume 12 Issue 1 January-June 2017

$1-1-2017$

\title{
Assessing the relative importance of employer branding dimensions on retention of employees: A case of private schools of Karachi
}

\author{
Faiza Sharif \\ Management Sciences Department, Shaheed Zulfiqar Ali Bhutto Institute of Science \& Technology \\ (SZABIST)
}

Saqib Sharif

Department of Economics and Finance, Institute of Business Administration

Follow this and additional works at: https://ir.iba.edu.pk/businessreview

Part of the Business Administration, Management, and Operations Commons

\section{cc) (7)}

This work is licensed under a Creative Commons Attribution 4.0 International License.

\section{Recommended Citation}

Sharif, F., \& Sharif, S. (2017). Assessing the relative importance of employer branding dimensions on retention of employees: A case of private schools of Karachi. Business Review, 12(1), 71-88. Retrieved from https://doi.org/10.54784/1990-6587.1050 


\title{
Assessing the relative importance of employer branding dimensions on retention of employees: A case of private schools of Karachi
}

\author{
Faiza Sharif · Saqib Sharif
}

\begin{abstract}
This study explores several dimensions of employer branding namely work environment, social aspect, compensation structure, development value and knowledge sharing in terms of their impact on the retention of employees with varying job tenures within the private schools of Karachi. The results of descriptive analysis, Pearson correlation, t-tests of independent populations and regression analysis reveal that Social Aspect and Development Values are the two most preferred dimensions of the employer brand, followed by Work Environment. The results of this research can be used by the education industry in developing human resource policies and practices that cultivate a learning and growth oriented culture and resultantly strengthen the employer brand.
\end{abstract}

Keywords Employer branding - Retention - Employer attractiveness · Human resource management.

\section{Introduction}

\subsection{Background}

The business environment is characterized by stiff competition and fast paced change. In such challenging times, organizations can be seen relying on human resources to provide the basis for sustainable competitive advantage. Companies are constantly on the lookout for capable and talented employees that they can attract and retain among their ranks. This task has become even more daunting as job hopping among high achieving individuals has become a very real phenomenon Alnıaçık and Alnıaçık (2012). In order to recruit and retain the best

Faiza Sharif

Management Sciences Department, Shaheed Zulfiqar Ali Bhutto Institute of Science \& Technology (SZABIST).

E-mail: faiza.sharif@szabist.edu.pk

Saqib Sharif

Department of Economics \& Finance, Institute of Business Administration (IBA)

(C)Sharif.F and Sharif, S. 2017 
possible talent, organizations are consciously adopting the holistic marketing concept of "Employer Branding" which assists the organizations in portraying themselves as the employer of choice for future employees and ensures organizational identification among current employees Berthon et al (2005).

\subsection{Employer branding(EB)}

The concept of "employer branding" has developed significantly in recent years Tüzüner and Yüksel (2009). The terminology was first coined by Ambler and Barrow (1996). They defined it as "the package of functional, economic, and psychological benefits provided by employment, and identification with the employing company". EB is also defined as the "sum of a company's efforts to communicate to existing and prospective staff that it is a desirable place to work" Lloyd (2002). Whereas, Martin et al (2005) defined it as "company's image seen through the eyes of its associates and potential hires, intimately linked to the "employment experience" of what is it like to work at a company, including tangibles such as salary and intangibles such as company culture and values".

"Every organization has an employer brand. Whether you own it or not, your organization is influencing its employer brand 365 days a year" Minchington and Thorne (2007). Brand management practices can be applied to a company's human resource management (HRM) if employees are viewed as buyers and the job position as the product Ambler and Barrow (1996). Employer Branding has been identified as one of the rare long-term solutions to the "shortage of talent" faced by organizations. It helps organizations to identify themselves as an employer of current staff, as a potential employer to new recruits and as a supplier or partner to customers.

Tüzüner and Yüksel (2009) have categorized the Employer Branding process into three steps. First, the central message of the organization must be incorporated into values which are to be offered to prospective and current employees. This is called Employee Value Preposition (EVP). It includes all unique qualities which differentiates the organization from its competitors such as organizational values, behavior, and culture. Next EVP must be efficiently marketed to the target group of candidates that the organization wants to attract. However, prior to this the organization needs to better understand the type of talent that is required based on its current status and future goals. Finally, the promises made by the employers in step one and two must be fulfilled for both the new employees attracted through this process and the existing employees. In this lies the core difference between Employer Branding and Corporate or Product branding, Employer Branding efforts are directed at both internal and external audiences, unlike corporate branding that targets only external audiences.

Picked from the business side of the enterprise it is the process of stamping an image of being a "great place to work" in the minds of existing and potential employees Berthon et al (2005). Employer Branding encompasses the usage of marketing research, public relations (PR), and advertising tools to modify the image of "what it is like to work at the organization". Employer Branding re- 
sults in devoted and engaged employees. Motivated employees perform to the best of their potential and this has a positive influence on customer satisfaction, which is extremely important particularly for the service sector.

Additional benefits of strong employer branding include more potential applicants, more internal recruitments, less time consumed in hiring, lower costs, reduced absenteeism and increased job satisfaction. This has a positive impact on the organization's product or services and the reputation of the corporate brand Beardwell and Claydon (2007).

Öster and Jonze (2013) suggest that organizations with a HR department are better positioned to create a strong employer brand. Employer branding clearly highlights the expectations of the firm and encourages only those applicants to apply who have the capabilities that match the firm's values. In addition, employer branding also contributes positively towards employee satisfaction and commitment by developing a strong culture through the HR policies and practices Edwards (2009), Backhaus and Tikoo (2004), Gaddam (2008).

\subsection{The dimensions of attraction \& retention in employer branding}

The competition for attracting and retaining high potential employees is quite similar to the competition for market share or customers Berthon et al (2005). Organizations are therefore focusing on identifying the dimensions which are important in attracting new employees, retaining the current employees and differentiating themselves from their competitors Alnıaçık and Alnıaçık (2012). Andersen (2008) supports the idea that attraction to an organization is influenced by the applicants' perception of the job and organizational characteristics such as salary, advancement and growth opportunities, location of work, career programs, and the structure of an organization.

Chapman et al (2005) in his study also found several factors which are essential in attracting and retaining employees such as type of work, working environment, image of an organization, person-organization fit and insight of the recruitment process. Kidrakarn (2014) argues that the factors which influence the retention of current employees are the pay rates, promotional opportunities, fair and transparent performance appraisal system, training and developmental prospects and working conditions. Berthon et al (2005) suggested five important dimensions that attract employees to an organization namely Work Environment, Social Aspect, Compensation Structure, Developmental Value and Knowledge Sharing.

Work Environment refers to the extent to which an organization offers its employees a working environment that is characterized by fun and happiness, novel work practices and an innovative culture that encourages the employees to exhibit creativity in performing their tasks. Social Aspect refers to the opportunity to establish good relations within the organization by the virtue of a team atmosphere, appreciation/recognition from the management, and good friendly relationships amongst the workers.

Compensation Structure encompasses the attraction that employees feel towards an organization as a consequence of the salary structure, compensation

Business Review: (2017) 12(1):71-88 
packages including perks, and job security. Developmental Value of an organization stems from the opportunities provided for career growth, recognition programs and facilitation of employees in building self-worth and confidence. Lastly Knowledge Sharing refers to the extent to which an employee is given the opportunity to apply and implement what they have learned through their experience and training, coaching and guiding other employees in the organization, and giving back to the society. Employer branding not only plays a major role in attracting a talented workforce for the organization Wilden et al (2010) but also positively influences the current employees instilling in them a sense of pride resulting in greater retention and less turnover Judson et al (2006).

\subsection{Objective of the study}

Intellectual capital forms the basis of a sustainable competitive advantage in today's economy of global competition and technological advancement. Organizations are striving hard to acquire and retain talented employees. This is only possible if the employer preposition offered is better than competitors. Therefore, we need to study the dimensions of attractiveness and retention in the workplace which are significant and positively contributing towards the greater achievement of organizational goals. The long term solution lies in building an employer brand to attract a continuous flow of talented workers.

The objective of this study is therefore to explore the importance of the dimensions of Employer branding namely work environment, social aspect, compensation structure, developmental value and knowledge sharing in terms of their significance in attracting new employees and retaining current employees. The findings of the study provide insights for organizations regarding the importance of employer branding. It imparts awareness of what is expected of organizations and what are the benefits associated with the adoption of employer branding.

\subsection{Scope and limitations}

The study focuses on the private schools located in Karachi. The theoretical scope is limited to studying employer branding in terms of how organizations are striving hard to make themselves the employer of choice. In relation to this the important dimensions taken into account for this study are work environment, social aspect, compensation structure, development values and knowledge sharing. Other than this there may be other factors as well that influence the employees' choice of an organization.

Due to time constraints the study covers organizations which are located in Karachi only. It focuses exclusively on employees who have less than one year of experience or employees who have between 3 to 5 years of experience. It also makes use of psychological knowledge because the response of potential or current employees in a similar setting may differ due to different personality types. 


\section{Literature review}

2.1 The employer brand as an instrument

Human capital is gaining significant importance as a basis for competitive advantage in organizations Macioschek and Katoen (2007). King and Grace (2008) believe that talented individuals possess skills, knowledge and experience which is of high economic value to the organization. As employees stay longer with the organizations, these skills, knowledge and experiences are enhanced and they become an asset for the organization that is too valuable to be lost. Therefore, organizations need to increase the commitment of their employees and also provide an environment in which the individuals chose to stay. In this connection, the employer brand is being used as an instrument by the companies to position themselves as an employer of choice.

Backhaus and Tikoo (2004) argue that employer branding has a twofold purpose: to attract potential employees and to sustain the commitment of current employees with the organization. Organizations are communicating their philosophy regarding human capital with the help of employer branding. EB also helps in creating brand loyalty and brand association. Backhaus and Tikoo (2004) conceptualized employer branding with a model shown in figure 1, which explains that brand association helps in creating a brand image of the organization which has an impact on the attractiveness of the firm. Any individual who associates himself with the firm image has more chances of applying to a vacant position. Therefore, organizations should communicate a strong message through employer branding to attract their required talent pool. Figure 1 also

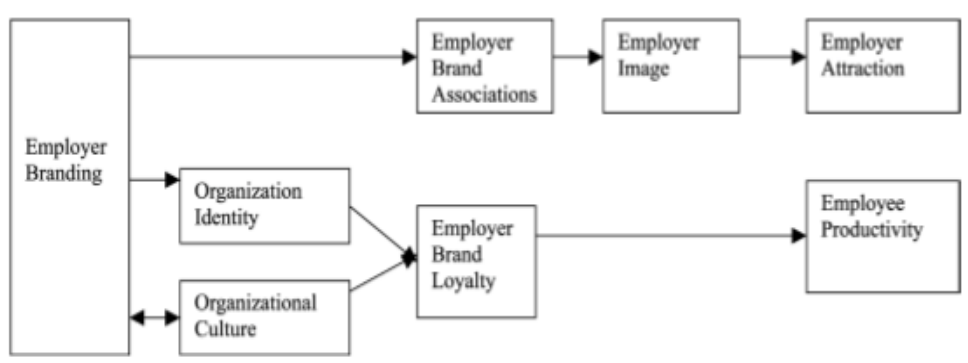

Fig. 1: Employer branding framework Backhaus and Tikoo (2004)

shows that the EB strategy influences organizational identity and organizational culture, which has an impact on employee loyalty. High level of employee loyalty leads to increased employee productivity. Employees that are committed to the organization feel attached to it and identify with its culture and values and therefore tend to stay longer with the organization.

Viktoria Rampl and Kenning (2014) studied employer personality in terms of sincerity, excitement, sophistication, ruggedness, and competence as shown in figure 2. They investigated the impact of these factors on attracting potential

Business Review: (2017) 12(1):71-88 
employees to the organization. They found that the personality trait "sincerity" has a higher influence on both trust and affect. However, ruggedness has a negative impact while all others have a positive impact. Hence, together brand affect and trust showed $71 \%$ variance in employer brand attractiveness.

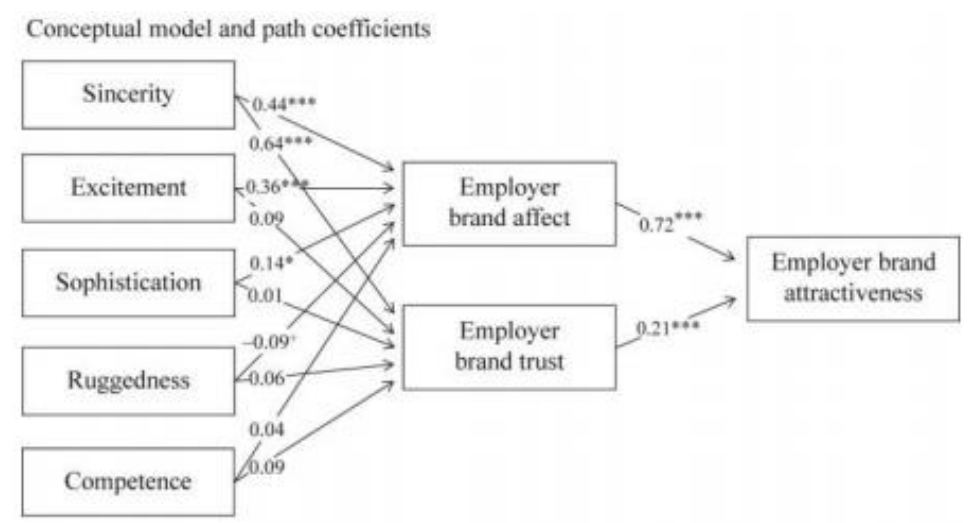

Fig. 2: Conceptual model and path coefficients Viktoria Rampl and Kenning (2014)

\subsection{The role of the human resources department}

Moroko and Uncles (2008) have emphasized that attracting and recruiting new employees and retention of current employees are both the core functions of the HR department in any organization. The HR department plays a critical role in managing the recruitment process efficiently and effectively with the help of the employer brand. The role of developing and communicating the employer brand is therefore often assigned to the HR department. The HR department should consider employment experience as a product which needs to be developed, managed and communicated properly to potential and current employees to maintain growth within the organization Moroko and Uncles (2008).

\subsection{Characteristics of successful employer brands}

The employer brand has to be strong enough to achieve its purpose of attracting potential employees and retaining current employees. It must therefore fulfill some criteria to build that competitive advantage for the firm. Moroko and Uncles (2008) state that the employer branding is similar to other types of branding, such as corporate or product branding that are characterized successful by their attractiveness and accuracy. A strong employer brand should also have the properties of being known and noticeable, relevant and resonant, and differentiated from its competitors Moroko and Uncles (2008). The other important 
characteristic of a strong employer brand is the fulfillment of the psychological contract between the employer and the employee that is agreed on during the recruitment process Backhaus and Tikoo (2004). If an existing employee is performing at required levels then they must be compensated, trained and developed in exchange for their performance.

Employer branding has several aspects which are suggested by Kapoor (2010) as depicted in figure 3. All these aspects contribute to making the employer brand stronger for instance an equitable reward system encourages employees to stay, strong vision and leadership provides direction, fairness and cooperation helps in the timely achievement of goals.

Maxwell and Knox (2009) discuss that there is a variation in essential char-

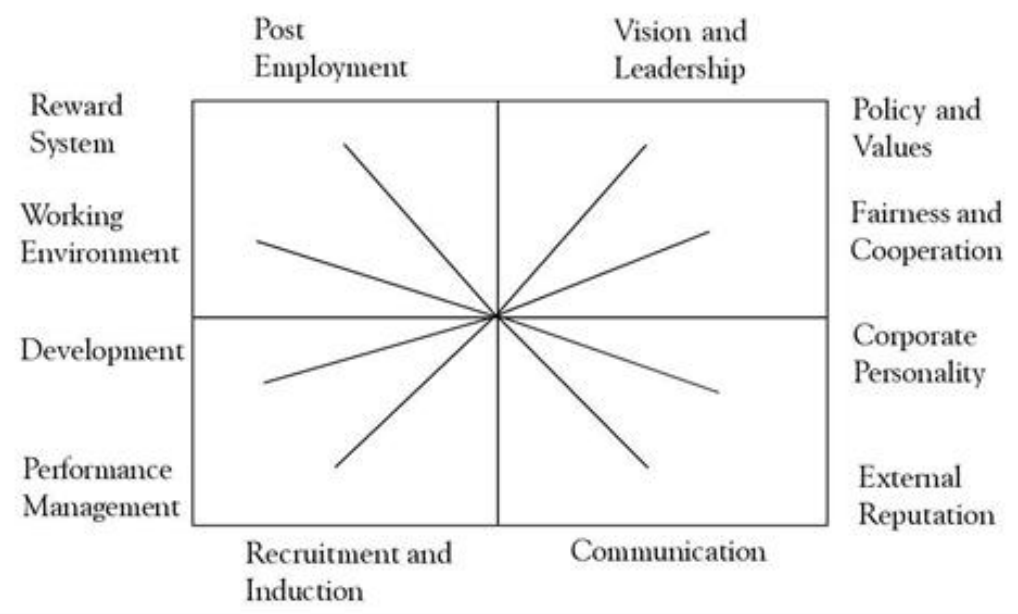

Fig. 3: Several aspects of employer branding Kapoor (2010)

acteristics such as the working environment, management style, collegial relationships, rewards, nature of work and workforce attributes between different organizations. Backhaus and Tikoo (2004) have divided the benefits of employer brand image into functional and symbolic benefits. Functional benefits include elements which are objectively desirable, such as the salary and economic benefits whereas the symbolic benefits are related to the subjective perceptions of the company and are identified as associations, ideas and feelings. EB can be used as a tool to communicate the symbolic benefits of a brand such as innovativeness and flexibility to potential employees; this helps in attracting candidates who identify with such values and benefits.

Furthermore, an important element of the employer brand is the character of an organization itself which includes the values, culture and principles which make the organization a collective entity. Potential employees are more prone to apply for organizations that have a favorable reputation Edwards (2009). Also the profitability of the company is seen as a critical feature in attracting potential employees.

King and Grace (2008) identify three aspects that employees look for in their

Business Review: (2017) 12(1):71-88 
employer of choice. These are training, customer/market information, and work environment/coworkers. The training helps employees to acquire the required skills to perform tasks effectively. Customer/ market information in the form of feedback creates awareness among the employees. Lastly, work environment/coworkers plays an important role in employees' retention, performance, transition and learning of new tasks.

\subsection{Realistic promises and employer branding as a retention tool}

The values and beliefs exhibited by the organizations to the potential and current employees' need to be satisfactory and authentic Backhaus and Tikoo (2004). If the promises communicated through the employer brand are not fulfilled, there are negative consequences in terms of dissatisfied employees leading to higher employee turnover. Mosley (2007) argues that in order to achieve its objectives, the characteristics and values of employer brand must be incorporated into the leadership and management styles of the organization. This will help in communicating and translating the values into everyday work practices of the employees.

King and Grace (2008) suggested an employee brand commitment pyramid $(\mathrm{EBCP})$ as shown in figure 4 . It explains that in order to retain and motivate employees to remain committed to the organization, the employer first needs to provide technical or task associated information, so that they can perform their tasks easily. This leads to commitment to their jobs. Employees who are then provided with appropriate brand-related information, however, move to the top of the pyramid as they develop a strong commitment to the brand. The continuity of organizational success and stainability of the strong brand is dependent on the degree to which employees are supported by the organization by providing access to brand related information. Priyadarshi (2011) has studied four

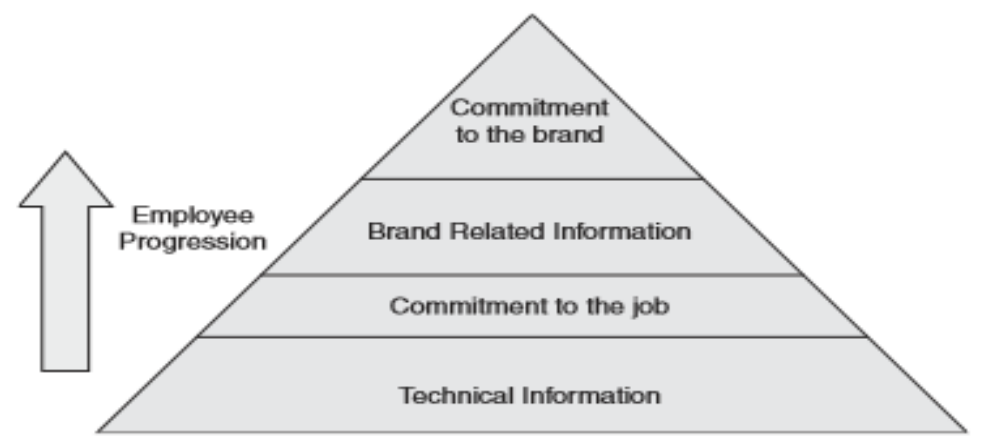

Fig. 4: Employee brand commitment pyramid (EBCP) King and Grace (2008)

important aspects of employer branding that have a significant impact on employee job satisfaction, affective commitment to the organization and intention to quit. These four aspects are: 1) organizational environment; 2) organizational 
fame and flexibility; 3) variety in job and work setting; and 4) compensation and career. Priyadarshi finds that only organizational fame and flexibility has a significant impact on employee job satisfaction. Love and Singh (2011) surveyed the top organizations in the world that claim to be the "employer of choice" and came up with eight common characteristics listed below:

1. Inspired leadership,

2. Strategic planning,

3. Employee communication,

4. Performance management,

5. Training and development,

6. Physical workspace, and

7. Corporate citizenship

There are many benefits of becoming the "employer of choice". These organizations are stable, enjoy a sustainable competitive advantage over competitors, and are hard to replicate. Other benefits include lower employee turnover, increase in the number of applicants, higher engagement levels from current employees, and better financial results.

\subsubsection{Teacher retention in schools}

Schools require highly qualified and trained teachers who remain with them for long periods of time to run successfully. The subject of teacher retention is gaining importance. Yost (2006) finds that the rate at which school teachers quit jobs within the first three years is unsatisfactorily high, standing at $33.5 \%$. This can be attributed to many factors including dissatisfaction with the existing job, and exploring other career options. Studies have also shown that teachers who are not provided with the proper learning and training techniques are more likely to leave the profession Darling-Hammond (2003). Many researches are now directed towards identifying ways of retaining already employed teachers to address this pressing issue. This will save the resources expended in continuously hiring and training new teachers.

Yost (2006) has further identified the factors which lead to decreased retention of school teachers. These include lack of proper resources and information, poor support by the management, and the discrepancy between the traditional practices of teacher education program curriculum and schools. Bobek (2002) has suggested five factors determining teachers' retention in schools. These are:

1. Relationship with administration and parents' support

2. Career growth

3. Personal ownership of the profession such as self-motivation to solve problems and set goals.

4. Sense of accomplishment

5. Temperament and spirit to face challenges

High turnover rate of qualified teachers affects the performance of students Berthon et al (2005). It has been observed that low achieving students are mostly taught by less qualified teachers. Moreover, qualified teachers are more

Business Review: (2017) 12(1):71-88 
likely to quit if not satisfied with the quality of the students. The geographical location of the school, i.e., the distance between the teacher's home and school also impacts retention.

\section{Research methodology}

\subsection{Research design and procedure}

This research follows a post positivism philosophy. The objective is to assess the relative importance of several dimensions of retention of current employees in the organizations and the results have been inferred by subsequent verification or falsification of the hypothesis. The research approach is deductive as it involves the development of a plan or typology prior to data collection and following a thorough literature review. The study is quantitative in nature and numerical data has been collected by means of a structured questionnaire.

The literature review provides the theoretical framework which has been used as a basis to develop the questionnaire. A pilot test was conducted before the questionnaires were distributed to collect the data. The questionnaire has been adapted from the study of Berthon et al (2005) and Firth et al (2004) with 32 items which are divided into 5 dimensions. The questionnaire was created on google.doc and circulated to respondents through email and also personally distributed in private schools. The respondents were given one week's time to respond to the questionnaire after which the respondent's score for each construct was coded on an excel sheet and imported on SPSS for further analysis. The constructs were summated and averages were taken for analysis. Further, the data is analyzed using tests such as Cronbach alpha, descriptive analysis, t-tests and regression analysis. This is followed by a discussion of the results and the paper concludes with recommendations and suggestions for future research.

\subsection{Population, sample and sampling method}

This study has two populations: teachers who have less than 1 year of experience and teachers with 3 to 5 years of experience in private schools of Karachi. Further, for the purpose of finding the number of teachers employed in each school, the researcher visited the websites of all private schools located in Karachi. Therefore the estimated population can be calculated as number of schools*average number of campus*average number of teachers in each campus (i.e., $210^{*} 3^{*} 30=18,900$; approximately 19,000 school teachers).

Proportionate quota sampling is used for the study. $50 \%$ respondents selected have less than 1 year of experience and $50 \%$ have working experience between 3 to 5 years. A structured survey questionnaire was developed containing both nominal and scale questions. The Likert scale was used to measure all the variables as it is a convenient way to comprehend the behavioral facets of individuals Sekaran and Bougie (2016). The scale varied from 1 (strongly disagree) to 5 (strongly agree) for all the questions. The independent variables for 
this research are: Work Environment, Social Aspect, Compensation Structure, Developmental Value, and Knowledge Sharing.

\subsection{Hypotheses}

H1: There is no significant difference in the importance of the five dimensionsnamely work environment, social aspect, compensation structure, developmental value, and knowledge sharing as assessed by employees with less than 1 year of experience and employees with 3 to 5 years of experience.

H2: There is no significant relationship between employer branding dimensions and retention of employees.

Following the development of hypotheses, the data was coded into different scales for further statistical analysis such as:

- Frequency distribution and percentages were analyzed for categorical questions such as gender, age, income etc.

- Descriptive analysis was performed on all constructs and sub-constructs to identify the participants overall opinion and deviations about the constructs.

- T-tests were conducted for assessing and identifying any difference of opinion regarding dimensions of employer branding between 2 different populations.

- Correlation analysis was performed to check the association between the variables.

- Regression analysis was done to identify the impact of explanatory variables on the dependent variable.

\section{Data analysis, findings and discussion}

The statistical test of Cronbach Alpha was applied to assess the reliability.

\subsection{Reliability and validity}

The questionnaire was evaluated for content and face validity. The content validity was determined by 2 domain experts and face validity was checked by experienced people in the human resource field. The survey questionnaire was

Table 1: Reliability of constructs

\begin{tabular}{lcc}
\hline Construct & Reliability & Items \\
\hline Work Environment & 0.856 & 8 \\
Social Aspect & 0.753 & 4 \\
Compensation Structure & 0.795 & 5 \\
Development Value & 0.854 & 4 \\
Knowledge Sharing & 0.764 & 3 \\
Employee Retention & 0.832 & 2 \\
\hline Overall & 0.928 & 26 \\
\hline
\end{tabular}

Business Review: (2017) 12(1):71-88 
distributed via email and in person to almost 400 participants, 207 questionnaires were returned of which 205 were usable making the response rate $51 \%$. The data was coded into nominal and scale variables to analyze the reliability which should be between $0-1$. The minimum Cronbach alpha must be $\geq 0.7$ for attaining internal consistency. Table 1 shows that the overall Cronbach alpha is 0.928. Each construct is also greater than 0.7. Hence, the data is reliable enough for further statistical analysis.

\subsection{Profiles of participants}

The profile of the participants was developed based on job experience, gender, age, and income. Table 2 summarizes the profile of the respondents. A total of

Table 2: Profile of respondents

\begin{tabular}{|c|c|c|c|}
\hline Profile & Groups & Frequency & \%ages \\
\hline \multirow[t]{2}{*}{ Job experience } & Less than 1 year & 54 & $26.60 \%$ \\
\hline & Between $3 \& 5$ years & 149 & $73.40 \%$ \\
\hline \multirow[t]{2}{*}{ Gender } & Male & 80 & $39.40 \%$ \\
\hline & Female & 123 & $60.60 \%$ \\
\hline \multirow[t]{4}{*}{ Age } & 2125 years & 47 & $23.20 \%$ \\
\hline & 2630 years & 60 & $29.60 \%$ \\
\hline & 3135 years & 65 & $32.00 \%$ \\
\hline & $>36$ years & 31 & $15.30 \%$ \\
\hline \multirow[t]{5}{*}{ Income } & less than Rs. 50,000 & 97 & $47.80 \%$ \\
\hline & Rs. 50,000 to Rs. 99,999 & 59 & $29.10 \%$ \\
\hline & Rs. 100,000 to Rs. 149,999 & 21 & $10.30 \%$ \\
\hline & Rs. 150,000 to Rs. 199,999 & 7 & $3.40 \%$ \\
\hline & Rs. 200,000 or more & 19 & $9.40 \%$ \\
\hline
\end{tabular}

205 respondents from various private schools of Karachi have responded of which $26.6 \%$ have job experience of less than 1 year and $73.4 \%$ have job experience between 3 and 5 years. $39.4 \%$ of the total respondents are males, while $60.6 \%$ are females. Majority of the respondents $(32.0 \%)$ are aged between $31 \& 35$ years. $(47.8 \%)$ of the respondents are earning less than Rs. 50,000 per month.

\subsection{Descriptive analysis and correlation}

The constructs of this study are developed on the 5 point Likert scale with 1 $=$ strongly disagree and $5=$ strongly agree. Table 3 shows the central tendency and measures of dispersion of the study variables. The overall mean has been computed by calculating the arithmetic mean or average of all the scales within the construct. The mean value of each variable indicates the contribution of the construct towards the study. Since all the variables have a mean greater than 3 therefore all the constructs are contributing positively towards the model for both the populations. The central tendency shows that all of the variables are close to the mean. However, the retention of employees in both groups exhibits a significant propensity to fluctuate which indicates that respondents 
Assessing the relative importance of employer ...

\begin{tabular}{|c|c|c|c|c|c|c|c|}
\hline & Job Experience & $\mathrm{N}$ & Min & $\operatorname{Max}$ & Mean & SD & SK \\
\hline \multirow[t]{7}{*}{$<1$ year } & Work Environment & 54 & 3 & 5 & 4.01 & 0.587 & -0.376 \\
\hline & Social Aspect & 54 & 1 & 5 & 4.06 & 0.686 & -1.805 \\
\hline & Compensation & 54 & 2 & 5 & 3.44 & 0.74 & -0.237 \\
\hline & Structure & & & & & & \\
\hline & Development Value & 54 & 2 & 5 & 3.57 & 0.7 & -0.365 \\
\hline & Knowledge Sharing & 54 & 2 & 5 & 3.86 & 0.613 & -0.623 \\
\hline & Retention & 54 & 1 & 5 & 3.24 & 1.054 & 0.071 \\
\hline \multirow[t]{7}{*}{3 to 5 years } & Work Environment & 149 & 2 & 5 & 3.97 & 0.698 & -0.603 \\
\hline & Social Aspect & 149 & 2 & 5 & 4.05 & 0.65 & -0.618 \\
\hline & Compensation & 149 & 2 & 5 & 3.47 & 0.793 & -0.315 \\
\hline & Structure & & & & & & \\
\hline & Development Value & 149 & 1 & 5 & 3.49 & 0.945 & -0.393 \\
\hline & Knowledge Sharing & 149 & 1 & 5 & 3.82 & 0.82 & -0.749 \\
\hline & Retention & 149 & 1 & 5 & 3.33 & 1.263 & -0.303 \\
\hline
\end{tabular}

have different opinions. Further, all the values are negatively skewed which shows that the mean is on the left side of the median except for retention in employees with less than 1 year of experience which is positive. The correlation

Table 4: Correlation within all the variables

\begin{tabular}{clcccccc}
\hline & Job Experience & Int & Soc & Eco & Dev & App & Ret \\
\hline$<1$ Year & Work Environment & 1 & & & & & \\
& Social Aspect & $.288^{*}$ & 1 & & & & \\
& Compensation & $.397^{* *}$ & $.523^{* *}$ & 1 & & & \\
& Structure & & & & & & \\
& Development Value & $.464^{* *}$ & $.460^{* *}$ & $.608^{* *}$ & 1 & & \\
& Knowledge Sharing & $.328^{*}$ & $.288^{*}$ & $.354^{* *}$ & $.546^{* *}$ & 1 & \\
& Retention & $.293^{*}$ & $.447^{* *}$ & $.428^{* *}$ & $.471^{* *}$ & 0.18 & 1 \\
Wo 5 Years & 1 & & & & & & \\
& Social Aspect & $.512^{* *}$ & 1 & & & & \\
& Compensation & $.576^{* *}$ & $.547^{* *}$ & 1 & & & \\
& Structure & & & & & & \\
& Development Value & $.627^{* *}$ & $.561^{* *}$ & $.656^{* *}$ & 1 & & \\
& Knowledge Sharing & $.511^{* *}$ & $.392^{* *}$ & $.460^{* *}$ & $.597^{* *}$ & & 1 \\
& Retention & $.457^{* *}$ & $.480^{* *}$ & $.442^{* *}$ & $.496^{* *}$ & $.344^{* * *}$ \\
\hline
\end{tabular}

matrix presents the results of both the groups. The results for employees with less than 1 year of experience show significant positive correlations among all the constructs except for knowledge sharing and retention. The highest correlation is between developmental value and retention in group one. In the second group, the results show high positive correlation amongst all the variables of the model. The highest correlation is between developmental value and retention and lowest is between knowledge sharing and retention of employees.

\subsection{T-test between 2 independent populations}

In table 5 it can be seen that all the employer branding dimensions exhibit $\mathrm{p}$-value $>0.05$. That means that the population variance is relatively equal for

Business Review: (2017) 12(1):71-88 
all EB dimensions for employees with less than 1 year experience and employees with 3 to 5 years' experience. Hence, the first null hypotheses (i.e., H1) is accepted.

\subsection{Regression analysis}

Based on t-test results, we do not find any difference of EB dimensions between the two groups of employees. Hence we conduct regression analysis on the whole sample to examine the relationship of EB dimensions with employees' retention. The regression result in table 6 shows that the adjusted R-square

Table 5: Regression analysis of employer branding dimensions on retention of employees

\begin{tabular}{lcccc}
\hline Dependent Variable: Employee Retention & \multicolumn{5}{c}{} \\
\hline & Coefficient & Standard Error & t-statistic & Sig \\
Intercept & -0.839 & 0.539 & -1.556 & 0.121 \\
Work Environment & $0.237^{*}$ & 0.138 & 1.718 & 0.087 \\
Social Aspect & $0.450 * *$ & 0.136 & 3.322 & 0.001 \\
Compensation Structure & 0.145 & 0.129 & 1.13 & 0.259 \\
Development Value & $0.285^{* *}$ & 0.126 & 2.266 & 0.024 \\
Knowledge Sharing & -0.04 & 0.118 & -0.335 & 0.738 \\
Adjusted R-Square & 0.281 & & & \\
No. of Observations & 205 & & & \\
Note: $* * *$, and $* * *$ & Significance & at the $10 \%, 5 \%$, and $1 \%$ level respectively
\end{tabular}

Table 6: Results of t-test for 5 dimensions between 2 populations

\begin{tabular}{lccccccccc}
\hline & F & Sig & t-stat & df & Sig & Mean Dif & SE Dif & Lower & Upper \\
\hline Work Environ & 3.806 & 0.052 & 0.384 & 201 & 0.701 & 0.041 & 0.107 & -0.169 & 0.251 \\
Social Aspect & 0.222 & 0.638 & 0.066 & 201 & 0.948 & 0.007 & 0.105 & -0.2 & 0.214 \\
Compen St & 0.219 & 0.64 & -0.246 & 201 & 0.806 & -0.03 & 0.124 & -0.274 & 0.214 \\
Develop Value & 5.933 & 0.016 & 0.586 & 201 & 0.559 & 0.082 & 0.141 & -0.195 & 0.36 \\
Know Sharing & 6.881 & 0.009 & 0.284 & 201 & 0.777 & 0.035 & 0.122 & -0.207 & 0.276 \\
\hline
\end{tabular}

$=.281$. Therefore, the dimensions of employer branding explain $28.1 \%$ of the variance in the criterion. Only three dimensions of employer branding are significant predictors, i.e., work environment, social aspect and developmental value. The results loosely lead to the rejection of null hypothesis (H6); as three out of five explanatory variables significantly impact employees retention. The work environment is weakly significant at $10 \%$ level, whereas, social aspect and developmental values are significant predictors of retention at $1 \%(\mathrm{p}$-value $<0.01)$ and $5 \%$ level ( $\mathrm{p}$-value $<0.05$ ) respectively.

Employer branding has a $30 \%$ impact on employees retention. The remaining $70 \%$ impact comes from other factors which have not been taken into account. Other variables which have greater impact on retention of employees include market success and vibrancy Tüzüner and Yüksel (2009) corporate social responsibility Pingle and Sharma (2013) and ergonomics of the organization Fassoulis and Alexopoulos (2015). 
4.6 Impact of employees' characteristics on retention

Lastly, we investigate the impact of employer branding on employees' retention when assessed with different employees' characteristics. For this purpose, we introduce three dummy variables for different characteristics of teachers, and run a separate regression analysis. First, we introduce a dichotomous variable for age: if age is between 21 years to 30 years (up to 30 years), the age dummy takes the value $=0$, otherwise 1 (i.e., age above 30 is equal to 1 ). Interestingly we find a significant positive effect of the age dummy on employee retention. Therefore, it can be said that employer branding initiatives produce better results when targeted at older teachers. The reason for this could be that older employees have family responsibilities and are thus less likely to switch jobs as compared to younger employees. The result is shown in table 7 .

Next we introduce the binary variable 0 for income up to Rs. 99,999 and 1 for income greater than Rs. 100,000. The regression results, not reported here, show insignificant impact of the income dummy. Hence, it can be said that employer branding initiatives have the same impact on retention of teachers with different income levels.

Finally, we also run regression analysis by introducing the dichotomous variable for gender, 0 for males and 1 for females, and find that results (gender dummy not different from zero) were the same for male and female population. ${ }^{1}$

Table 7: Regression analysis with employee age dummy

\begin{tabular}{|c|c|c|c|c|}
\hline \multicolumn{5}{|c|}{ Dependent Variable: Employee Retention } \\
\hline & Coefficent & Standard error & t-statistics & Significant \\
\hline Intercept & -0.851 & 0.529 & -1.608 & 0.109 \\
\hline Age_Dummy & $0.420^{* * *}$ & 0.144 & 2.914 & 0.004 \\
\hline Work Environment & $0.238^{*}$ & 0.135 & 1.758 & 0.08 \\
\hline Social Aspect & $0.444^{* * *}$ & 0.133 & 3.333 & 0.001 \\
\hline Compensation Structure & 0.081 & 0.128 & 0.63 & 0.53 \\
\hline Development Value & $0.328 * * *$ & 0.124 & 2.638 & 0.009 \\
\hline Knowledge Sharing & -0.063 & 0.116 & -0.545 & 0.587 \\
\hline Adjusted R-Square & 0.307 & & & \\
\hline No. of Observations & 205 & & & \\
\hline
\end{tabular}

\section{Conclusion, recommendations and areas for future research}

The results of this research validate the widely accepted paradigm proposed by Pingle and Sharma (2013) that strong employer branding develops a lasting relationship with the employees that ensures the retention, loyalty, commitment and advocacy of employees. Employer branding is not only the responsibility of the HR and marketing department but has to be ingrained in all aspects of the organization and reflected in its culture and traditions.

1 The results are available upon request from the author. 
In this study, we examined the impact of five dimensions of employer branding (work environment, social aspect, compensation structure, developmental value, and knowledge sharing) on the retention of employees with varying years of work experience. Based on the results of the $t$ tests, we do not reject the null hypothesis as there is no significant difference in the employer branding dimensions between two groups of employees categorized according to years of work experience.

The regression analysis reveals that three dimensions of employer branding namely work environment, social aspect and developmental value are significant predictors of employee retention. School management should therefore focus on devising novel work practices and innovative culture that encourages teachers to exhibit creativity (i.e., work environment); have better mentoring practices, reward team work and allow for socializing activities on the job (i.e., social aspect); provide opportunities for career growth, recognition programs, and assist employees in building self-worth and confidence (i.e., development value). Lastly, we find that middle aged teachers respond better to employer branding and their retention ratio in private schools is higher than that of younger teachers.

These results have important managerial implications for human resource practices with respect to retention of employees. Understanding the different dimensions of employer branding and examining the importance of each dimension to the current employees with varied job experience can facilitate the human resources department to develop more suitable messages, policies, and benefits.

Both population groups have given significant importance to the "social aspect" which refers to building strong and supportive relationships with organizational members. Also recognition is important as it has been valued more than compensation structure.

Similar research can be carried out in a different industry or at a different level so that the results of the framework can be validated to determine generalizability. This research has been conducted using demographic characteristics of gender, age and income level. In subsequent researches, other demographic characteristics such as, level of education and employment duration can be explored as moderating factors. Furthermore, future research can also assess the impact of the employer brand on post-employment dissonance.

\section{References}

Alnıaçık E, Alnıaçık Ü (2012) Identifying dimensions of attractiveness in employer branding: effects of age, gender, and current employment status. Procedia-Social and Behavioral Sciences 58:1336-1343

Ambler T, Barrow S (1996) The employer brand. Journal of brand management 4(3):185-206

Andersen HC (2008) Employer attractiveness: what effect does csr have, and how can organizations become attractive to norwegian business students? Master's thesis

Backhaus K, Tikoo S (2004) Conceptualizing and researching employer branding. Career development international 9(5):501-517

Beardwell J, Claydon T (2007) Human resource management: A contemporary approach. Pearson Education 
Berthon P, Ewing M, Hah LL (2005) Captivating company: dimensions of attractiveness in employer branding. International journal of advertising 24(2):151-172

Bobek BL (2002) Teacher resiliency: A key to career longevity. The Clearing House 75(4):202205

Chapman DS, Uggerslev KL, Carroll SA, Piasentin KA, Jones DA (2005) Applicant attraction to organizations and job choice: a meta-analytic review of the correlates of recruiting outcomes.

Darling-Hammond L (2003) Keeping good teachers: Why it matters, what leaders can do. Educational leadership 60(8):6-13

Edwards MR (2009) An integrative review of employer branding and ob theory. Personnel review 39(1):5-23

Fassoulis K, Alexopoulos N (2015) The workplace as a factor of job satisfaction and productivity: a case study of administrative personnel at the university of athens. Journal of Facilities Management 13(4):332-349

Firth L, Mellor DJ, Moore KA, Loquet C (2004) How can managers reduce employee intention to quit? Journal of managerial psychology 19(2):170-187

Gaddam S (2008) Modeling employer branding communication: The softer aspect of hr marketing management. ICFAI Journal of Soft Skills 2(1)

Judson KM, Gorchels L, Aurand TW (2006) Building a university brand from within: A comparison of coaches' perspectives of internal branding. Journal of Marketing for Higher Education 16(1):97-114

Kapoor V (2010) Employer branding: A study of its relevance in india. IUP Journal of Brand Management 7

Kidrakarn K (2014) Employer branding for successful recruitment and retention of talented academic staff in thai universities. PhD thesis, Victoria University

King C, Grace D (2008) Internal branding: Exploring the employee's perspective. Journal of Brand Management 15(5):358-372

Lloyd S (2002) Branding from the inside out. Business Review Weekly 24(10):64-66

Love LF, Singh P (2011) Workplace branding: Leveraging human resources management practices for competitive advantage through best employer surveys. Journal of Business and Psychology 26(2):175

Macioschek A, Katoen R (2007) Employer branding and talent-relationship-management: Improving the organizational recruitment approach

Martin G, Beaumont P, Doig R, Pate J (2005) Branding:: A new performance discourse for hr? European Management Journal 23(1):76-88

Maxwell R, Knox S (2009) Motivating employees to" live the brand": a comparative case study of employer brand attractiveness within the firm. Journal of marketing management 25(910):893-907

Minchington B, Thorne K (2007) Measuring the effectiveness of your employer brand. Human Resources Magazine 12(4):14-16

Moroko L, Uncles MD (2008) Characteristics of successful employer brands. Journal of Brand Management 16(3):160-175

Mosley RW (2007) Customer experience, organisational culture and the employer brand. Journal of Brand Management 15(2):123-134

Öster H, Jonze J (2013) Employer branding in human resource management: The importance of recruiting and retaining employees

Pingle SS, Sharma A (2013) External employer attractiveness: A study of management students in india. Journal of Contemporary Management Research 7(1):78

Priyadarshi P (2011) Employer brand image as predictor of employee satisfaction, affective commitment \& turnover. Indian Journal of Industrial Relations pp 510-522

Sekaran U, Bougie R (2016) Research methods for business: A skill building approach. John Wiley \& Sons

Tüzüner VL, Yüksel CA (2009) Segmenting potential employees according to firms employer attractiveness dimensions in the employer branding concept. Journal of Academic Research in Economics 1(1):46-61

Viktoria Rampl L, Kenning P (2014) Employer brand trust and affect: linking brand personality to employer brand attractiveness. European Journal of Marketing 48(1/2):218-236

Wilden R, Gudergan S, Lings I (2010) Employer branding: strategic implications for staff recruitment. Journal of Marketing Management 26(1-2):56-73

Business Review: (2017) 12(1):71-88 
https://ir.iba.edu.pk/businessreview/vol12/iss1/5

DOI: https://doi.org/10.54784/1990-6587.1050

F. Sharif, S. Sharif

Yost DS (2006) Reflection and self-efficacy: Enhancing the retention of qualified teachers from a teacher education perspective. Teacher Education Quarterly 33(4):59-76 